\title{
A Comparative Study of the Organic Acid Content of the Hemolymph of Schistosoma mansoni-Resistant and Susceptible Strains of Biomphalaria glabrata
}

\author{
José Clecildo Barreto Bezerra/ ${ }^{+}$, Wilhelm Becker*, Ulrike E Zelck*
}

\begin{abstract}
Departamento de Parasitologia, Instituto de Patologia Tropical e Saúde Pública, Universidade Federal de Goiás, Rua Delenda Rezende de Melo s/nọn, Setor Universitário, 74605-050 Goiânia, GO, Brasil *Zoologisches Institut und Zoologisches Museum der Universität Hamburg, Martin-Luther-King-Platz 3, Hamburg, 20146, Germany
\end{abstract}

The freshwater snail Biomphalaria glabrata is an intermediate host of the trematode Schistosoma mansoni. However, some strains of B. glabrata are resistant to successful infection by $\mathrm{S}$. mansoni larvae. The present work examines the profile of organic acids present in $\mathrm{S}$. mansoni-resistant and -susceptible strains of $\mathrm{B}$. glabrata, in order to determine whether the type of organic acid present is related to susceptibility. The organic acids were extracted from the hemolymph of two susceptible $\mathrm{B}$. glabrata strains (PR, Puerto Rico and Ba, Jacobina-Bahia from Brazil), and from the resistant strains 13-16- $R_{1}$ and $10 R_{2}$, using solid phase extraction procedures followed by high performance liquid chromatography. The organic acids obtained were analyzed and identified by comparison with known standards. Pyruvate, lactate, succinate, malate, fumarate, acetate, propionate, $\beta$-hydroxybutyrate and acetoacetate were detected in all hemolymph samples. Under standard conditions, the concentration of each of these substances varied among the strains tested and appeared to be specific for each strain. An interesting variation was the low concentration of pyruvate in the hemolymph of PR-snails. Only the concentration of fumarate was consistently different $(\mathrm{p} \leq 0.05)$ between resistant and susceptible strains.

Key words: Biomphalaria glabrata - host-parasite interaction - organic acids - resistance - Schistosoma mansoni - susceptibility

Mollusk-parasite relationships represent a vast field of research. Several studies have examined the influence of parasites on the host organism (Marshall et al. 1974, McManus \& James 1975, Becker 1980), the mechanisms of host location (MacInnis et al. 1974, Haas 1985), and the mollusk's resistance to the parasite, i.e. incompatibility of the host (Wright 1974, Richards 1975, Bayne \& Loker 1987, Zelck et al. 1995, Boehmler et al. 1996). In general, mollusks represent important intermediate hosts for the multiplication of trematode larvae. In case of Schistosoma mansoni, the larvae can multiply to reach a weight equivalent up to $50 \%$ of that of the Biomphalaria glabrata digestive gland (Schwanbek et al. 1986). $S$. mansoni larvae obtain their energy and growth substrates from the host, and in exchange release products of their intermediate metabolism into the host's body. For larval growth to occur, alterations

This study was supported in part by $\mathrm{CNPq}$, Brazil and DAAD, Germany.

${ }^{+}$Corresponding author. Fax: +55-62-261.6414

Received 1 August 1996

Accepted 11 November 1996 are required in the host's own metabolism (Becker 1980).

Many aspects of the host-parasite interaction remain to be clarified. Parasites such as $S$. mansoni relay on one specific host, in this case $B$. glabrata. The host itself may possess factors which determine whether an infection will be successful. Resistant $B$. glabrata possess a natural defense system which protects them against $S$. mansoni larvae, which generally die one to three days after penetrating the snails. Although susceptible snails are able to protect themselves against disease-transmitting agents, $S$. mansoni appears to be able to avoid the snail's defense system, thus allowing its own development in the host.

Organic acids are important components of intermediate metabolism and participate in both catabolic (eg. glycolysis) and anabolic (eg. gluconeogenesis) pathways. Pyruvate and lactate are indicators of glycolytic processes under aerobic conditions, while fumarate, succinate and malate are indicators of the tricarboxylic acid cycle. The presence of ketone bodies, such as B-hydroxybutyrate and acetoacetate, as well as of fatty acids, such as acetate and propionate, is indicative for lipid metabolism (Meyer et al. 1986, Bezerra \& Becker 1993). 
The present work reports on the concentration of organic acids in the hemolymph of non-infected B. glabrata and examines whether there is any difference in the intermediate metabolism of resistant and susceptible snails. Since the development of the larva in the host depends on hemolymph components, we hypothesize a relationship between the profile of organic acids present and the snail's ability to resist the parasite.

\section{MATERIALS AND METHODS}

B. glabrata were maintained in 30 liters aquaria under standard conditions, at a density of 30 snails per tank. Water temperature was maintained at $26 \pm 2^{\circ} \mathrm{C}$ and the animals were kept on a 12 hr light: dark cycle. The snails were fed ad libitum with a balanced diet (Becker \& Lamprecht 1977). Only adult snails with a shell diameter of $18 \pm 2 \mathrm{~mm}$ were used in the study.

Two S. mansoni-susceptible strains (PR, Puerto Rico, and Ba, Jacobina-Bahia) and two S. mansoniresistant strains (13-16- $\mathrm{R}_{1}$ and $10 \mathrm{R}_{2}$ ) of $B$. glabrata were employed.

Sample preparation - Hemolymph collection: the snail's shell was first cleaned with a paper towel and the hemolymph then collected with a Pasteur pipette inserted through a tiny hole made in the pericardial region of the shell. The hemolymph from three snails was pooled and then centrifuged $\left(120 \mathrm{~g}, 5 \mathrm{~min}, 2^{\circ} \mathrm{C}\right)$, in order to remove hemocytes and cellular debris. The resulting supernatant was used in the analyses described below. A total of ten samples from each strain was examined.

Extraction and separation of the organic acids - The organic acids were extracted immediately from the centrifuged hemolymph using Bond -Elut ${ }^{\circledR}$ columns (SAX-anion exchange-quartenary amine, manufactured by Analytichem International, Habor City, USA) as described by Rumsby et al. (1987). Under vacuum, the columns were activated by consecutive washes with $1 \mathrm{ml}$ of $0.5 \mathrm{M}$ $\mathrm{HCl}, 1 \mathrm{ml}$ of methanol and $2 \mathrm{ml}$ of HPLC-grade water. They were loaded with $200 \mu \mathrm{l}$ of hemolymph and $2 \mathrm{ml}$ water. The columns were disconnected from the vacuum pump and $250 \mu \mathrm{l}$ of $0.5 \mathrm{M}$ sulphuric acid were applied to elute the organic acids retained on the matrix. The eluate was centrifuged at $1200 \mathrm{~g}$ for $5 \mathrm{~min}$ and the supernatant stored at $-70^{\circ} \mathrm{C}$ until analysis by high performance liquid chromatography.

The liquid chromatography (HPLC-system Milton Roy-Analyst 7800) was performed at room temperature using a BIORAD-Aminex ion exclusion HPX-87H column (300x7.8 mm) designed specifically for the separation of organic acids. The separation column was protected by a BIORADAminex HPX-85 guard column. The mobile phase was sulphuric acid $(0.5 \mathrm{mM})$ delivered at a flow rate of $0.8 \mathrm{ml} / \mathrm{min}$. The elution profile was determined at $210 \mathrm{~nm}$. The injection volume of each sample was $100 \mu \mathrm{l}$.

Statistical calculations were based on the nonparametric U-test of Wilcoxon, Mann and Whitney (Sachs 1986). The differences were considered to be significant when $p \leq 0.05$.

\section{RESULTS}

The organic acids pyruvate, lactate, succinate, fumarate, malate, acetate, propionate, acetoacetate and $\beta$-hydroxybutyrate were detected in the hemolymph of all B. glabrata strains under normal conditions. Figure shows the level of each of these substances in the hemolymph samples and provides a statistical comparison of the results obtained. With the exception of fumarate, there was no consistent difference in the levels of these acids between $S$. mansoni-susceptible and resistant strains of B. glabrata.

\section{DISCUSSION}

The various studies of host-parasite compatibility published so far are not always comparable because of the wide variety of methods and experimental designs employed (Frandsen 1979).

Our extraction method is commonly used in the medical field for urine and blood analyses and the evaluation of physiological disorders in man (Rehman et al. 1982). By adapting the methodology to invertebrates, it was possible to separate and quantify nine organic acids at the same time in one sample of B. glabrata hemolymph. These acids represent metabolites directly linked to energy production and facultative metabolic ways in invertebrates (Ishak et al. 1975, Patience et al. 1983, Hardewig et al. 1994).

Under the conditions employed, the four strains studied showed different concentrations of organic acids, the profiles of which appeared to be specific for each strain. Gilbertson et al. (1967) also reported variations in the amino acid concentrations of $B$. glabrata strains from different geographical locations.

An interesting finding in the present work was the low concentration of pyruvate in the susceptible strain PR. Pyruvate is the end product of the glycolytic process and serves as a substrate for the formation of acetyl-CoA, which will either enter the Krebs' cycle or form acetate or lactate. The low concentration of pyruvate in the PR strain may therefore be explained as a less intensive glycolytic rate than in resistant snails, or by its faster usage as a substrate and hence faster removal from the hemolymph of susceptible snails.

The success of both the parasite's penetration 
a) PYRUVATE

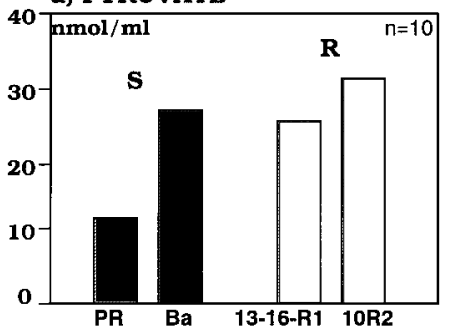

c) SUCCINATE

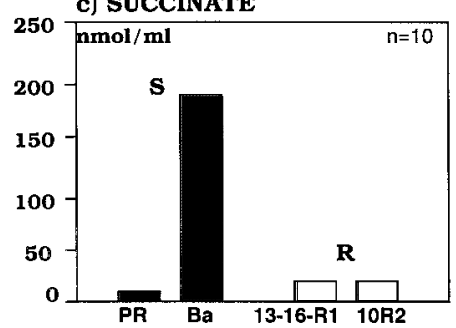

e) MALATE

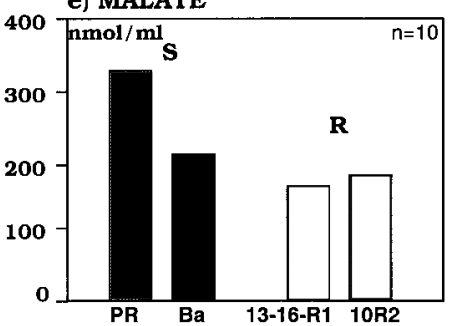

g) PROPIONATE

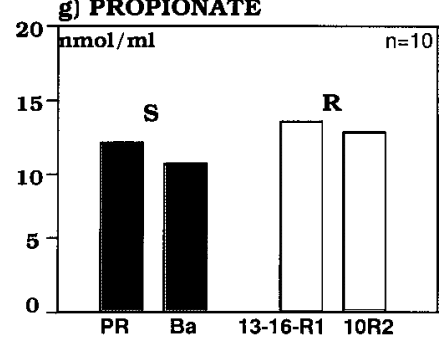

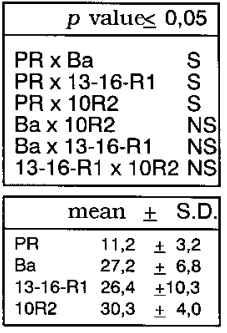

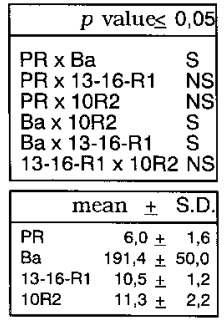

d) FUMARATE

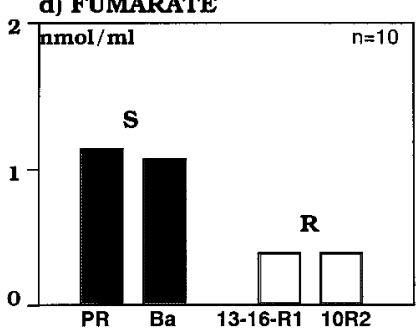

f] ACETATE

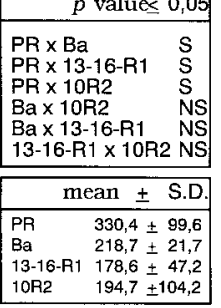

$\begin{array}{ll}10 \mathrm{R} 2 & 178,6 \pm 47,2 \\ 10404,2\end{array}$

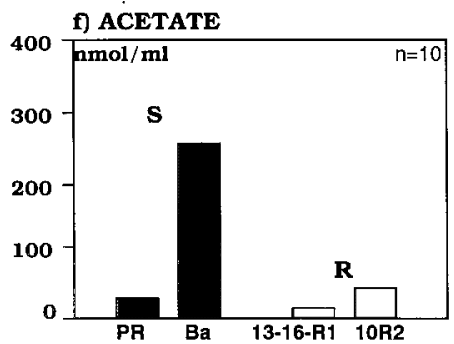

b) LACTATE

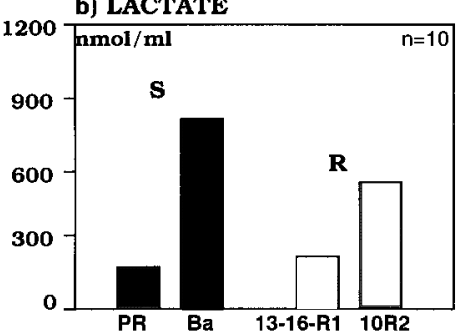

\begin{tabular}{|c|c|}
\hline \multicolumn{2}{|c|}{$p$ value $\leq 0,05$} \\
\hline $\begin{array}{l}\mathrm{PR} \times \mathrm{Ba} \\
\mathrm{PR} \times 13 \\
\mathrm{PR} \times 10 \\
\mathrm{Ba} \times 10 \\
\mathrm{Ba} \times 13 \\
13-16-\mathrm{R}\end{array}$ & $\begin{array}{ll} & \mathrm{S} \\
16-\mathrm{R} 1 & \mathrm{NS} \\
72 & \mathrm{~S} \\
22 & \mathrm{~S} \\
16-\mathrm{R} 1 & \mathrm{~S} \\
1 \times 10 \mathrm{R} 2 & \mathrm{~S}\end{array}$ \\
\hline & $\tan \pm$ \\
\hline $\begin{array}{l}\mathrm{PR} \\
\mathrm{Ba} \\
13-16-\mathrm{R} 1 \\
10 \mathrm{R} 2\end{array}$ & $\begin{array}{l}212,3 \pm 80,7 \\
832,5 \pm 109,6 \\
245,0 \pm 66,6 \\
552,0 \pm 135,8\end{array}$ \\
\hline
\end{tabular}

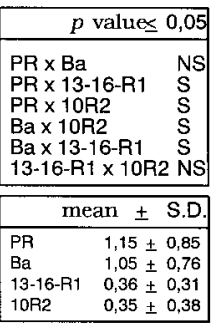
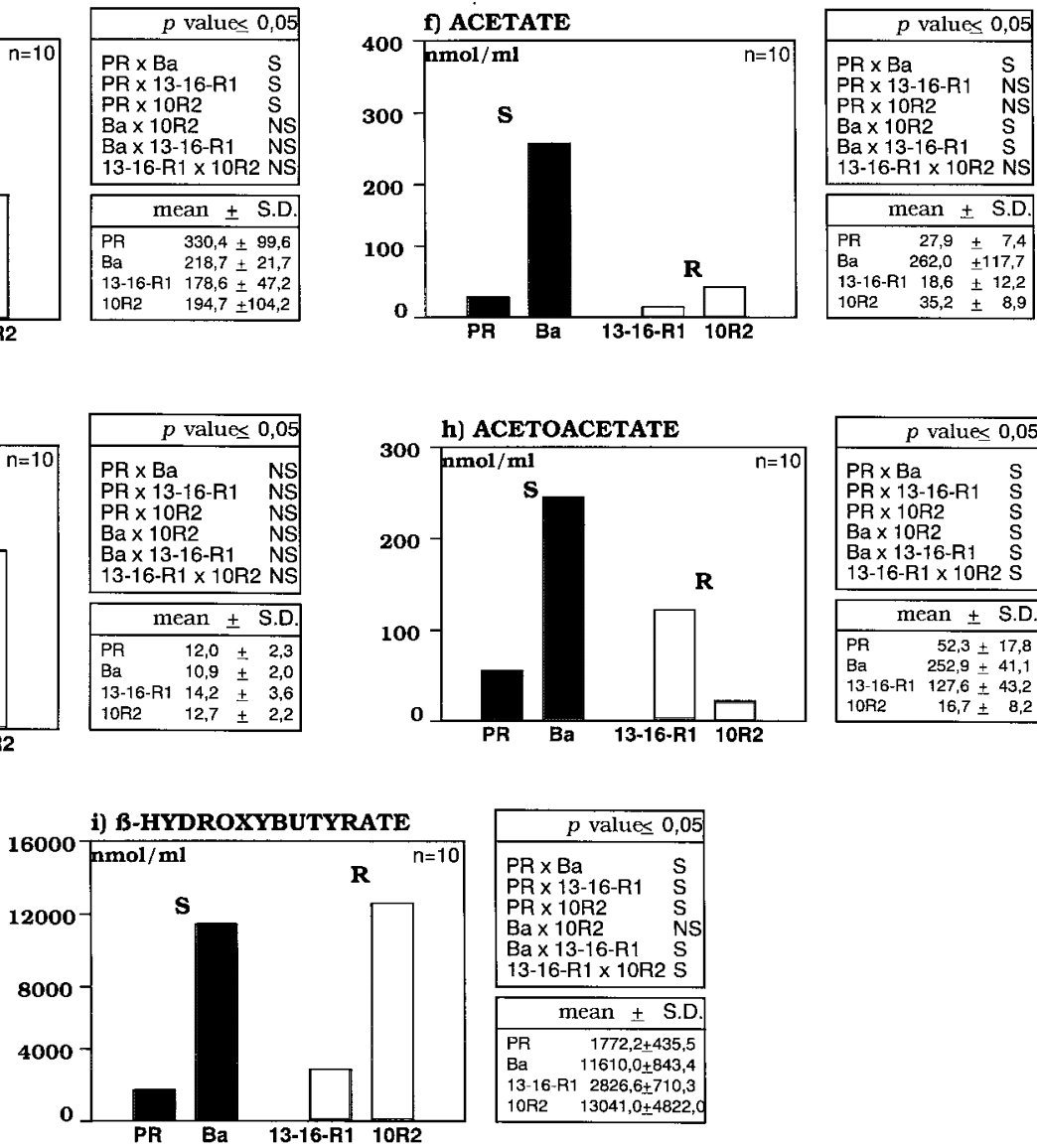

The organic acids concentrations. Pyruvate (a), lactate (b), succinate (c), fumarate (d), malate (e), acetate (f) and propionate (g); and of the ketone bodies acetoacetate (h) and ß-hydroxybutyrate (i) in Schistosoma mansoni-susceptible (S) and resistant (R) strains of Biomphalaria glabrata. PR, Puerto Rico. Ba, Bahia. The values shown are the mean \pm S.D. Significant differences $(p \leq 0.05)$ are marked by $\mathrm{S}$ while non-significant differences are indicated by NS. 
of the snail's skin (Loker \& Bayne 1982, Bayne \& Loker 1987) and the establishing of an infection (Frandsen 1979) are generally correlated with the hemolymph composition. In this context, it is possible that the parasite is able to absorb host substances which will provide either energy or structural substrates to enable the parasite to become established (Wright 1974). The presence of parasite-repelling substances may indicate either a host metabolic state not condutive to the parasite's settling or the presence of important concentration differences for certain substrates.

The concentration of lactate showed no distinctive profile between susceptible and resistant snails. The strains $\mathrm{Ba}$ and $10 \mathrm{R}_{2}$ both had a high level of this acid. Flechter and LoVerde (1981) suggested a correlation between $S$. mansoni lactate dehydrogenase values and the parasite's infectivity in snails. However, the results shown here indicate no difference in the hemolymph lactate levels of susceptible and resistant snails.

Only for fumarate we detected a consistent significant difference between resistant and susceptible strains. It is interesting to note that the fumarate-reductase system is gaining increasing attention in invertebrate biochemistry. Particularly the presence of this system has a valuable physiological meaning in the adaptation of invertebrates with facultative anaerobic metabolism under adverse ecological conditions and is very important in the studies of helmith parasites metabolism to elucidate the characteristics of the fumarate-reductase system in relation to energy generation and to the effects of anthelmintics on the energy metabolisms (Takamiya et al. 1984, 1993, Tielens 1994, Saz 1990, Kita 1992). In conclusion, the results of this work show a variable concentration of organic acids in the hemolymph of $S$. mansoni-resistant and -susceptible strains of B. glabrata. These differences cannot be correlated with the snail's ability to eliminate the parasite.

\section{ACKNOWLEDGEMENTS}

To Mr Andreas Kemper for his helpful discussions and to Dr W Lobato Paraense for supplying the Bahia strain.

\section{REFERENCES}

Bayne CJ, Loker ES 1987. Survival within the snail host, p. 321-346. In D Rollinson, AJG Simpson (eds), The biology of the schistosomes. From genes to latrines. Academic Press, London.

Becker W 1980. Metabolic interrelationships of parasitic trematodes and molluscs, especially Schistosoma mansoni in Biomphalaria glabrata. Z Parasitenkd 63: 101-111.

Becker W, Lamprecht I 1977. Mikrokalorimetrische Untersuchungen zum Wirt-Parasit-Verhältnis zwischen Biomphalaria glabrata und Schistosoma mansoni. Z Parasitenkd 53: 297-305.

Bezerra JCB, Becker W 1993. Konzentration organischer Säuren in der Hämolymphe von Biomphalaria glabrata unter verschiedenen physiologischen Zuständen. Verh Dtsch Zool Ges 86: 81.

Boehmler AM, Fryer SE, Bayne CJ 1996. Killing of Schistosoma mansoni sporocysts by Biomphalaria glabrata hemolymph in vitro: Alteration of hemocyte behavior after poly-L-lysine treatment of plastic, and the kinetics of killing by different host strains. $J$ Parasitol 82: 332-335.

Flechter M, LoVerde PT 1981. Schistosoma mansoni: electrophoretic characterization of strains selected for different levels of infectivity to snails. Exper Parasitol 52: 362-370.

Frandsen F 1979. Discussion of the relationships between Schistosoma and their intermediate hosts, assessment of the degree of host-parasite compatibility and evaluation of schistosome taxonomy. $Z$ Parasitenkd 58: 275-296.

Gilbertson DE, Etges FJ, Odle JD 1967. Free amino acids of Australorbis glabratus hemolymph: Comparison of four geographic strains and effect of infection by Schistosoma mansoni. J Parasitol 53: 565568.

Haas W 1985. Bilharziose: die biologische und biotechnische Bekämpfung einer Tropenkrankheit. Verh Dtsch Zool Ges 78: 45-60.

Hardewig I, Pörtner HO, Grieshaber MK 1994. Interactions of anaerobic propionate formation and acidbase status in Arenicola marina: an analysis of propionyl-CoA carboxylase. Physiol Zool 67: 892909.

Ishak MM, Mohamed AM, Sharaf AA 1975. Carbohydrate metabolism in uninfected and trematode-infected snails Biomphalaria alexandrina and Bulinus truncatus. Comp Biochem Physiol 51B: 499-505.

Kita K 1992. Electron-transfer complexes of mitochondria in Ascaris suum. Parasitol Today 8: 155-159.

Loker ES, Bayne CJ 1982. In vitro encounters between Schistosoma mansoni primary sporocysts and hemolymph components of susceptible and resistant strains of Biomphalaria glabrata. Am J Trop Med Hyg 31: 999-1005.

MacInnis AJ, Bethel WM, Cornford EM 1974. Identification of chemical of snail origin that attract Schistosoma mansoni miracidia. Nature 248: 361-363.

Marshall I, McManus DP, James BL 1974. Glycolysis in the digestive gland of healthy and parasitized Littorina saxatilis rudis (Maton) and in the daughter sporocysts of Microphallus similis (Jäg) (Digenea: Microphallidae). Comp Biochem Physiol 49: 291-299.

McManus DP, James BL 1975. Aerobic glucose metabolism in the digestive gland of Littorina saxatilis rudis (Maton) and in the daughter sporocysts of Microphallus similis. Z Parasitenkd 46: 265-275.

Meyer R, Becker W, Klimkewitz M 1986. Investigations on the ketone body metabolism in Biomphalaria glabrata: Influence of starvation and of infection with Schistosoma mansoni. J Comp 
Physiol B 156: 563-571.

Patience RL, Thomas JD, Sterry PR 1983. Production and release of carboxylic acids during oxic and anoxic metabolism by the pulmonate snail Biomphalaria glabrata (Say). Comp Biochem Physiol 76B: 253-262.

Rehman A, Gates SC, Webb JW 1982. Comparison of isolation methods of urinary organic acids by highperformance liquid chromatography. Chromathography 228: 103-112.

Richards CS 1975. Genetic factor in susceptibility of Biomphalaria glabrata for different strains of Schistosoma mansoni. Parasitology 70: 231-241.

Rumsby G, Belloque J, Ersser RS, Seakins JWT 1987. Effect of temperature and sample preparation on performance of ion-moderated partion chromatography of organic acids in biological fluids. Cli Chim Acta 163: 171-183.

Sachs L 1986. Statistische Auswertungsmethoden. Springer-Verlag, Berlin, 545 pp.

Saz HJ 1990. Helminths: Primary models for compara- tive biochemistry. Parasitol Today 6: 92-93.

Schwanbek A, Becker W, Rupprecht H 1986. Quantification of parasite development in the host-parasite system Biomphalaria glabrata and Schistosoma mansoni. Z Parasitenkd 72: 365-373.

Takamiya S, Furushima R, Oya H 1984. Electron transport systems of the mitochondrial fraction in the freshwater snail Biompahalaria glabrata. Comp Biochem Physiol 77B: 465-473.

Takamiya S, Kita K, Wang H, Weinstein PP, Hiraishi A, Oya H, Aoki T 1993. Developmental changes in the respiratory chain of Ascaris mitochondria. Biochim Biophys Acta 1141: 65-74.

Tielens AGM 1994. Energy generation in parasitic helminths. Parasitol Today 10: 346-352.

Wright CA 1974 . Snail susceptibility or trematode infectivity? J Nat Hist 8: 545-548.

Zelck UE, Becker W, Bayne CJ 1995. The plasma proteins of Biomphalaria glabrata in the presence and absence of Schistosoma mansoni. Dev Comp Immunol 19: 181-194. 
426 Organic Acids of Biomphalaria glabrata - JCB Bezerra et al. 